International Journal of Current Advanced Research

ISSN: O: 2319-6475, ISSN: P: 2319 - 6505, Impact Factor: SJIF: 5.995

Available Online at www.journalijcar.org

Volume 6; Issue 4; April 2017; Page No. 3107-3109

DOI: http://dx.doi.org/10.24327/ijcar.2017.3109.0195

Research Article

\title{
REASONING BEHIND THE REDNESS - AN INSIGHT TO PEMPHIGUS VULGARIS
}

\section{Nandhini V1., Santhosh Kumar ${ }^{2}$., Gayathri ${ }^{3}$ and Aparnna Suresh ${ }^{4}$}

1Sathyabama University Dental College\& Hospital Chennai

2Dr Santhosh Dental Organisation, Chennai

${ }^{3}$ Sathyabama University Dental College\& Hospital, Chennai

${ }^{4}$ Vydehi Institute of Dental Science and Research Centre, Bangalore

\section{A R T I C L E I N F O}

\section{Article History:}

Received $17^{\text {th }}$ January, 2017

Received in revised form $8^{\text {th }}$ February, 2017

Accepted $22^{\text {nd }}$ March, 2017

Published online $28^{\text {th }}$ April, 2017

\begin{abstract}
A B S T R A C T
Erosive gingival lesions associated with vesiculobullous disease such as Lichen Planus, Cicatrical pemphigoid and pemphigus vulgaris have been collectively referred to as "Desquamative Gingivitis" Here we report a case of 63 year old female patient suffering from exacerbation and remission of pemphigus vulgaris since last 6 months. This case report emphasizes detailed case roprt, thorough oral and systemic examinations, investigative measures and proper treatment regimen.
\end{abstract}

\section{Key words:}

Desquamative gingivitis, Pemphigus vulgaris,

Stress, Corticosteroid therapy.

Copyright $₫ 2017$ Nandhini $V$ et al. This is an open access article distributed under the Creative Commons Attribution License, which permits unrestricted use, distribution, and reproduction in any medium, provided the original work is properly cited.

\section{INTRODUCTION}

Pemphigus vulgaris is chronic autoimmune vesiculobullous lesions primarily affecting the oral mucosa and then spreads to the other parts of the body. The autoantibodies are directed against desmoglein 1 and 3 proteins present in the desmosomes resulting in the lack of cohesion in between the cells. Clinically appears as bullae that ruptures easily and exhibit positive nikolsky sign due to the accumulation of transudative fluid between the desmosomes and the basement membrane. ${ }^{1}$ There is a complex interplay between the genetic and environmental factor in the pathogenesis of pemphigus vulgaris. In genetically predisposed individuals it occurs spontaneously or induced by the triggering factors such as infection, trauma or sunlight and stress ${ }^{2}$. Here we report a case of pemphigus vulgaris with the only oral manifestations and its possible co-realation with the stress also reviewed.

\section{CASE REPORT}

A 63 year old female patient reported to the dental clinic with the chief complaint of frequent blister formation followed by ulceration, pain and burning sensation for the past 6 months which refrained her from eating regular diet. Patient also noticed excaberation of these ulcerations whenever she is stressed up.

\section{*Corresponding author: Nandhini V}

Sathyabama University Dental College\& Hospital Chennai
Patient had undergone full mouth extraction due to chronic periodontitis and has been restored with complete denture. Extra oral examination showed no relevant changes. Intra oral examination revealed irregular shaped ulcer involving the right buccal mucosa that extends from the angle of the mouth to the retromolar area with erythematous border which was tender on palpation (figure1).

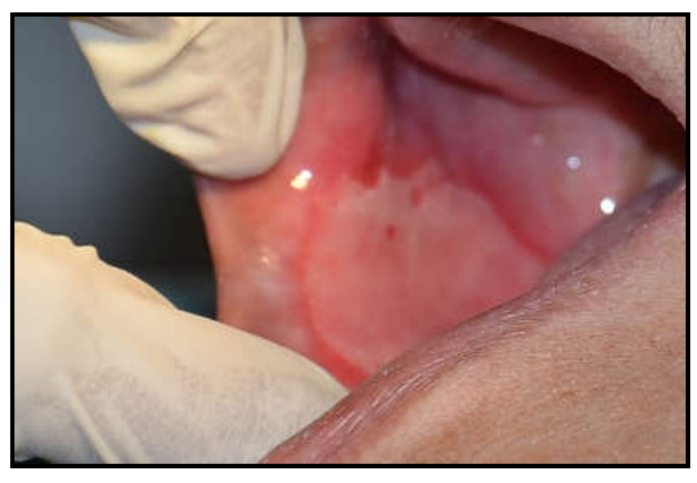

Figure 1 Pre Operative View

From the clinical perspective the provisional diagnosis of pemphigus vulgaris and erosive lichen planus was made. The latter was of less suspect as we could not see wickhams striae in this patient. The other reasons of chronic ulcerations are herpetic gingivostomatitis, pemphigoid. After informed consent perilesional biopsy was taken from the buccal mucosa for conventional histology and direct immunoflourescent examination. Histopathology showed stratified squamous epithelium, with intraepithelial separation, and the nuclei was 
round and hyperchromatic. Underlying connective tissue showed band of mild chronic inflammatory cell infiltrate with the areas of vasularity and haemorrhage (fig2). Direct immunoflourescent section showed positive intercellular staining for immunoglobulin $\mathrm{G}$ in the stratum sspinosum and the keratinocyte layer of the stratified squamous epithelium layer(fig 3).
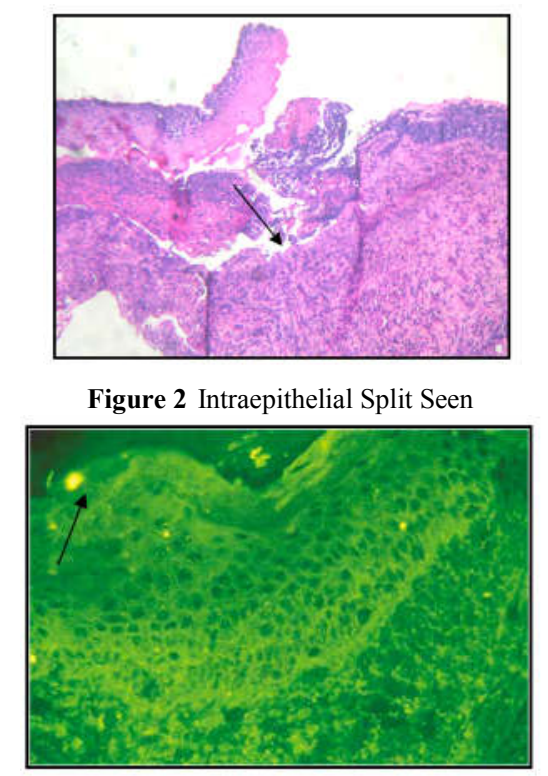

Figure 3 Positive Intracellular Staining For Igg In the Stratum Spinosum and the Keratinocyte Layer

From the above said clinical and histological evaluation the final diagnosis of pemphigus vulgaris was made. Patient was adviced rest for a week. Patient was prescribed topical steroids (kenacort $0.1 \%$ ) for a month. Dermatological consultation was taken and the dermal involvement was ruled out. Patient was then prescribed $40 \mathrm{mg}$ of corticosteroid for one month. The lesion improved considerably after the first week of steroid therapy. From the inference of previous studies about pemphigus vulgaris it was understood that disease activity decreases with time and most cases of recurrence occur in first two years. ${ }^{3}$ Hence forth patient was asked to come for review every 2 week for 6 months time and no new recurrence of lesion was observed till date.

\section{DISCUSSION}

Desquamative gingivitis (DG) is characterized by erythematous gingiva, desquamation and erosion of the gingival epithelium, and blister formation. ${ }^{4}$ Pemphigus vulgaris, oral lichen planus and Mucous membrane pemphigoid are the common autoimmune blistering lesions causing chronic oral ulceration prevalently affecting the fourth and the fifth decade female. Pemphigus vulgaris always affects the mouth and it can be the initial site of presentation. It clinically presents as flaccid fluid filled blisters similar to other vesiculobullous lesions but with thin roof which rapidly breakdown to form painful eroded areas. The most affected anatomical sites included buccal, alveolar and soft palate mucosal areas, corresponding to $75 \%$ of all biopsies.

The etiology of pemphigus vulgaris is the presence of circulating IgG antibodies against the desmosomal cadhedrin proteins desmoglein 1 and desmoglein 3 seen in the stratified squamous epithelium which leads to formation of bullae in the skin and the mucous membrane respectively. Desmoglein3 are abundantly present in oral mucous membrane and are responsible for maintaining the mucosal integrity. Loss of tolerance against desmoglein 3 in both the $\mathrm{T}$ cell and B cell are responsible for acantholysis in the epithelium. The appearance of autoantibodies against desmoglein1 heralds the development of more severe disease and moderate involvement. Genetic predisposition is known to be associated with human leukocyte antigens (HLA), in particular with DR4, 14; DQ 1, 3. However genetic predisposition alone is not enough to induce the autoimmune entity, it necessitates the presence of initiating factors such as allergens, infection, neoplasms and drugs to set off the full blown disease. ${ }^{6}$ Here in the case report careful enquiry was made to rule out the initiating factors and was identified that stress was the main triggering factor for the oral presentation. The onset of oral ulceration coincided with the history of stress. Definitive diagnosis of Pemphigus vulgaris requires the clinical and the immunological stains done in the biopsy specimens taken from the perilesional area. ${ }^{7}$ The loss of adhesiveness in the spinous cell layer due to anti desmoglein 3 antibody results in intraepithelial bullae formation and acantholysis in a 27 year study on clinical pathogenesis of autoimmune disease. ${ }^{6,8}$

The level of circulating autoantibodies in the indirect immunoflorescent study is directly propotional to the severity of the disease and effectiveness of the treatment instituted. Oral Systemic corticosteroids are the main stay of the treatment for pemphigus vulgaris, though the lesion is restricted to the mouth, pertaining to the decline in the mortality rate. ${ }^{[9]}$ The optimal dose, route and weaning of steroids differs depending on the severity of the lesion. The dose of systemic steroids vary from $20 \mathrm{mg}-70 \mathrm{mg}$ which is modified on individual basis, taking account of the age and general health of the patient and the extent of the disease. Treatment must be regularly reviewed and attempts made to reduce and ultimately withdraw all treatment if possible.

The use of intravenous immunoglobulin (IVIg) has been recently reported to be successful in treatment of immune mediated lesion, in whom conventional therapy had failed or produced significant and disabling side-effects. But multicentre trial is required to warrant the role of intravenous immunoglobin therapy in the management of patients with pemphigus vulgaris. ${ }^{10}$

The role of stressor events in aggravating vesiculobullous lesion is well established. ${ }^{11}$ Psychological stress might alter immune function through direct innervations of lymphatic tissue, through release of hypothalamic pituitary adrenocortical axis (HPA) and sympathetic adrenal medull ary (SAM) hormones that bind to and alter the functions of immunologically active cells, or through stress-induced behavioural changes. ${ }^{12}$ Henceforth recognizing the influence of psychological stress on the development and evolution of pemphigus is important, since the health condition of the patients can be improved through the recognition, validation and treatment of their psychological issues, associating psychological assistance to the immunosuppressive treatment. ${ }^{13}$ 


\section{CONCLUSION}

Dentists could be the first health professionals to recognize the mucosal involvement disorder. Correct diagnosis of the condition entails taking a detailed history, coupled with a thorough intraoral and extra oral examination, along with histopathology and Immunofluoroscence studies, contributing to the improved treatment outcome. Psychological stress has been associated with the course of several autoimmune skin diseases and reported a possible factor in triggering and aggravating for pemphigus in predisposed patients. Practically, avoiding or limiting the interaction of environmental factors with the pemphigus-prone genetic background maybe a useful precaution in the management of these patients, as it improves the efficacy of conventional treatments, reduce risks of relapses, and, in some cases, even result in a cure.

\section{References}

1. N. A. Robinson, JF Yeo, YS Lee. Oral Pemphigus Vulgaris: A case report with literature update. Annals Academy of Medicine 2004: 33; 63- 68.

2. V. Ruocco, E. Ruocco, Pemphigus and environmental factors, Gital Dermatol Venereol 2003; 138: 299-309.

3. Kyriakis KP, Tosca AD. Epidemiologic observations on the natural course of pemphigus vulgaris. Int $J$ Dermatol 1998; 37:215-9.

4. Robinson NA, Wray D. Desquamative gingivitis: a sign of mucocutaneous disorders-a review. Aust Dent $J$ 2003; 48: 206-11.
5. Emília Angela Loschiavo Arisawa, Janete Dias Almeida, Yasmin Rodarte Carvalho, Luiz Antonio Guimarães Cabral. Clinicopathological analysis of oral mucous autoimmune disease: A 27-year study. Med Oral Patol Oral Cir Bucal. 2008 Feb1; 13(2): 94-7.

6. Bystryn JC, Rudolph JL. Pemphigus. Lancet. 2005 Jul 2-8; 366(9479): 61- 73.

7. Black M, Mignogna MD, Scully C. Number II. Pemphigus vulgaris. Oral Dis. 2005 May; 11(3) : 11930.

8. Bagan J, Lo Muzio L, Scully C. Mucosal disease series. Number III. Mucous membrane pemphigoid. Oral Dis. 2005 Jul; 11(4): 197- 218.

9. Scully C, Challacombe SJ, Pemphigus vulgaris, Update on etiopathogenesis, oral manifestations and management. Crit Rev Oral Biol Med, 2002, 13, 397408.

10. Sami N, Bhol KC, Ahmed AR. Treatment of oral pemphigoid with intravenous immunoglobulin as monotherapy Long-term follow-up: influence of treatment on antibody titres to human a 6 integrin Clin Exp Immunol 2002; 129: 533-40.

11. Picardi A, Abeni D. Stressful life events and Skin diseases: Disentangling evidence from Myth. Pschother Psychosom 2001; 70: 118-36.

12. Cohen S, Janicki-Deverts D, Miller GE. Psychological Stress and Disease. JAMA 2007; 298: 1685-7.

13. Aline Bicalho Matias, Ana Maria Ferreira Roselino. Pemphigus and psychological stress: a review of the literature. Our Dermatol Online. 2013; 4(Suppl. 3): 616- 618.

\section{How to cite this article:}

Nandhini V et al (2017) ' Reasoning Behind The Redness-An Insight to Pemphigus Vulgaris', International Journal of

Current Advanced Research, 06(04), pp. 3107-3109.

DOI: http://dx.doi.org/10.24327/ijcar.2017.3109.0195 